\title{
Topographical thresholds for ephemeral gully initiation in intensively cultivated areas of the Mediterranean
}

\author{
L. Vandekerckhove ${ }^{\mathrm{a}, *}$, J. Poesen ${ }^{\mathrm{a}, \mathrm{b}}$, D. Oostwoud Wijdenes ${ }^{\mathrm{a}}$, \\ T. de Figueiredo ${ }^{\mathrm{c}}$

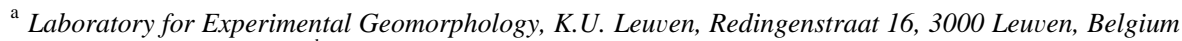 \\ ${ }^{\mathrm{b}}$ Fund for Scientific Research, Flanders, Belgium \\ ${ }^{\mathrm{c}}$ Escola Superior Agraria de Bragança, Apartado, 172, P-5300 Bragança, Portugal
}

Received 6 March 1997; accepted 13 May 1998

\begin{abstract}
Ephemeral gullying is an important erosion process in Mediterranean areas suffering from land degradation because of increased drought and human impact. An ephemeral gully is formed when a hydraulic threshold for incision into a resistant soil surface is exceeded. The flow intensity at the soil surface of any landscape position is controlled by topographical parameters, such as local slope $(S)$ and drainage-basin area $(A)$. The objective of this study was to investigate to what extent one could use field measurements of $S$ and $A$ to predict the location of ephemeral gully initiation in intensively cultivated Mediterranean environments. Two relatively homogeneous study areas in Southeast Spain and Northeast Portugal with widespread ephemeral gullying were selected. $S$ and $A$ were measured by standard methods at the initiation point of 50 ephemeral gullies in each study area. The relationship between $\mathrm{S}$ and A was statistically investigated. On a double logarithmic scale, the $S$ and $A$ data showed considerable scatter. Orthogonal regression resulted in the threshold relationship $S=a A^{-b}$ with $b=0.133$ for Spain, and $b=0.226$ for Portugal. The analysis also showed that $S$ and $A$ were weakly correlated for the Spanish dataset, and more strongly correlated for the Portuguese dataset. The correlation was considerably strengthened by including additional information on planform curvature and on tillage direction relative to the gully direction. Greater soil stoniness and the presence of a less permeable horizon generally increased the threshold level in both study areas. The threshold relationships resulting from this study were compared with literature data. The indices $A_{\mathrm{c}} S$ and $\ln \left(A_{\mathrm{c}} / S\right)$ were applied to our study sites but neither relationship individually described the general trend between the data
\end{abstract}

\footnotetext{
* Corresponding author. Fax: +32-31163226400; E-mail: liesbeth.vandekerckhove@geo.kuleuven.ac.be
} 
of $S$ and $A$. Therefore, an alternative index, $A_{\mathrm{c}}^{b} S$, with $0.133 \leq b \leq 0.226$, according to the empirical trend between drainage basin area and local slope, was proposed to describe the topographical threshold conditions for ephemeral gully initiation in similar Mediterranean areas. (C) 1998 Elsevier Science B.V. All rights reserved.

Keywords: Gully; Spain; Portugal; Slope gradient; Drainage area; Rock fragments; Impermeable horizon; Tillage direction

\section{Introduction}

Gully erosion is responsible for significant amounts of soil loss from Mediterranean catchments (e.g., Poesen et al., 1996; Poesen and Hooke, 1997), and more generally can be considered as an indicator of desertification (UNEP, 1994). Many modern land use practices increase soil erodibility in these environments (Cammeraat and Imeson, 1995). Often, the soil surface is exposed to erosion because it remains uncovered for part or all of the year. Also land abandonment and afforestation can increase gully erosion (e.g., Faulkner, 1995; Lopez-Bermudez, 1996). Without the implementation of specific soil conservation measures, various types of gully erosion such as ephemeral gullies or bank gullies (Poesen et al., 1996) can occur. In the Mediterranean region the spatial and temporal variability of the rainfall pattern is being enhanced by prolonged drought periods on the one hand, and by an increased number of intensive storms on the other (Geeson and Thornes, 1996). Consequently, erosion is being increased by unpredictable rainfall events as well as by increasingly bare, dry, erodible soil.

This study is particularly concerned with ephemeral gully erosion. An arbitrary minimum channel cross-section of $930 \mathrm{~cm}^{2}\left(1 \mathrm{ft}^{2}\right)$ is used to distinguish rills from gullies (Poesen, 1993; Hauge, 1977). These incisions may occur each year, depending on the magnitude of the local rainfall events, but are easily erased by tillage activities. They usually start off as rills, but their cross-section may exceed $930 \mathrm{~cm}^{2}$ until sedimentation occurs 20 to $50 \mathrm{~m}$ downslope on average. Such erosion features are not directly linked with the permanent drainage system, but create an important sediment stock at the bottom of agricultural fields, generally equal to or greater than that from other water erosion processes. Erosion plot studies at different sites within the Mediterranean area have shown relatively low soil loss rates from interrill and rill erosion (Kosmas et al., 1997), whereas Poesen et al. (1996) estimated that soil loss by ephemeral gully erosion from two sites in Southeast Portugal and Southeast Spain accounted for 80 and $83 \%$, respectively, of the total sediment production in small catchments.

However, ephemeral gully erosion is not accounted for in simple erosion predicting tools such as the RUSLE (Renard et al., 1994), and is included only in a few process-based erosion models such as WEPP (Flanagan and Nearing, 1995) and EGEM (USDASCS, 1992). Moreover, both EGEM and WEPP require the input of landscape positions where the initiation of an ephemeral gully is expected. To meet these modelling as well as conservation planning requirements, a simple means for predicting the location of ephemeral gully initiation is needed. Because the threshold event leading to gully formation is very complex in process terms and difficult to asses, a simple field 
index based on quantitative empirical relations can provide an alternative solution, avoiding time-consuming and expensive process studies.

The threshold concept for erosion by overland flow was first stated by Horton (1945), i.e., that incision only occurs where a threshold of soil resistance to flow shear stress is exceeded. He defined the 'length of overland flow' as the distance over which run-off will flow before concentrating into permanent drainage channels. This topographical characteristic of a drainage system can be interpreted as a measure of surface resistance to concentrated flow erosion. Based on this concept, Schumm (1956) defined the 'constant of channel maintenance' as the minimum limiting area required for the development of a drainage channel. Begin and Schumm (1979) expressed the combined role of drainage area and valley slope by a 'shear stress indicator' for the definition of valley floor instability, modified after methods used by Patton and Schumm (1975) and by Brice (1966). Gully initiation occurs above a threshold value of the shear stress indicator within uniform geomorphic and hydrologic conditions. Different threshold values are expected where geology, soils, climate and vegetation are different. The concept is based on an inverse relationship between drainage area and valley slope, describing the threshold for gully initiation. Similar relationships have been observed and interpreted in terms of process theory for incision into resistant surfaces by Hortonian overland flow, saturation overland flow and landsliding by Montgomery and Dietrich (1988, 1994) and Prosser and Abernethy (1996). Despite the large scatter between the parameters drainage area and slope, the threshold concept seems to provide a simple and useful tool for predicting the location of gully initiation in concentrated flow areas. Rutherfurd et al. (1997) used this topographical threshold to specify the limiting extent of gully erosion, whereas Moore et al. (1988) predicted the location of the entire ephemeral gully trajectory using two topographical indices relating to subsurface and overland flow.

The cited literature shows that there has already been much research on the role of topographical attributes in the gully incision process and on the corresponding threshold relationships, for instance between drainage area and local slope. However, many differences can be revealed between the studied erosion features, the data collection methods and analysing procedures. Hence, the resulting threshold conditions are difficult to compare (Vandaele et al., 1996). The investigated and predicted erosion features include a freshly formed ephemeral gully head, the head of an old (Holocene) stabilised gully as well as the course of an entire ephemeral gully. Generally, most or all topographical attributes are derived from topographical maps or Digital Terrain Models (DTMs), and the collection of field data is confined to local slope measurements (see overview given by Vandaele et al., 1996). Few datasets have been collected entirely by field measurements, though these can provide a more realistic insight into ephemeral gully formation. For instance, ephemeral gullies on straight slopes or formed in linear landscape elements are often overlooked, and most research has been focused on gullies in topographical hollows that can readily be modelled using a DTM.

Given the importance of ephemeral gully erosion in intensively cultivated Mediterranean areas, and the lack of field data on topographical thresholds for ephemeral gully initiation in this environment, the objectives of this study were (1) to measure local slope $(S)$ and drainage-basin area $(A)$ in the field at the initiation point of ephemeral 
gullies, formed mainly by overland flow within one season in a fairly homogeneous, intensively cultivated Mediterranean environment, (2) to verify to what extent these field measurements of $S$ and $A$ can be used to predict the location of ephemeral gully initiation by deriving a threshold relationship and a simple topographical index, and (3) to investigate the influence of local soil properties on the threshold relationship.

\section{Study areas}

Field data were collected in two intensively cultivated Mediterranean areas situated in the Guadalentin basin in Southeast Spain and around the city of Bragança in Northeast Portugal (Fig. 1). The Guadalentin basin is representative of many Mediterranean semi-arid to arid environments under threat of desertification (Fig. 2a). The surveyed ephemeral gullies were located in the lower part of the Rambla del Chortal catchment, which drains from the Sierra de la Torrecilla into the Rio Corneras, a tributary of the Rio Guadalentin. The West-East oriented mountain chains in this region belong to the Betic Range. The geological formations in the study area belong to the 'Complejo Malaguide,' dominated by shales, greywackes, conglomerates and other sedimentary rocks ('pelitas'). These result in shallow soils with very stony $\mathrm{A} / \mathrm{C}$ or $\mathrm{A}_{\mathrm{p}}$ horizons (between 50 and $90 \%$ rock fragments by mass) over fragmented bedrock (Puigdefábregas et al., 1996), classified as Eutric, Mollic and Lithic Leptosols. The area consists of rounded landforms with an altitude range of 520 to $960 \mathrm{~m}$, and moderate to fairly steep slopes. The ephemeral gullies occurred on slopes of $9-56 \%$ with a mean value of $26 \% \pm 10.4$. The main land-use in the Rambla del Chortal is almond cultivation, which is increasingly replacing the existing scrubland vegetation (matorral) (Poesen et al., 1997), but unproductive almond groves or other agricultural land are also being abandoned and are in different stages of regeneration with natural vegetation. Hence, natural forests exist in the area beside the more widespread pine plantations. Our survey included only ephemeral gullies in intensively cultivated almond groves. These are ploughed 3 to 5 times a year to control weeds and conserve water. The climate of the Guadalentin basin is mainly semi-arid, with a mean annual precipitation of $225-483 \mathrm{~mm}$. In the Rambla del Chortal, the estimated mean annual precipitation is $300-330 \mathrm{~mm}$ (Puigdefábregas et al., 1996). Most of the rain falls in autumn and spring, often as high intensity storms with a very erratic spatial distribution (Cabezas, 1996).

The study area in Portugal is a plateau area east of the Serra da Nogueira, stretching to the north and south of Bragança (Fig. 2b). The plateau is strongly dissected by the Rio Sabor river system, resulting in very variable relief and a wide valley around Bragança city. The overall altitude ranges from about $500 \mathrm{~m}$ in the lowest valley to 1300 $\mathrm{m}$ on the highest crest. The area has a rolling appearance, with gentle to moderately steep slopes. The sampled slope range varies between 4.5 and $31 \%$ with a mean value of $15.3 \% \pm 5.7$. The bedrock is dominated by schists, with patches of mafic and ultramafic rocks, sedimentary deposits, granites and quartzites. The dominant soils are Leptosols derived from schists or granites, and Chromic Luvisols derived from basic rocks. They are associated with Cambisols on gentle slopes, and Regosols in colluvial areas. Alisols occur on sedimentary deposits, and Fluvisols in alluvial valleys. Land use in the area is 


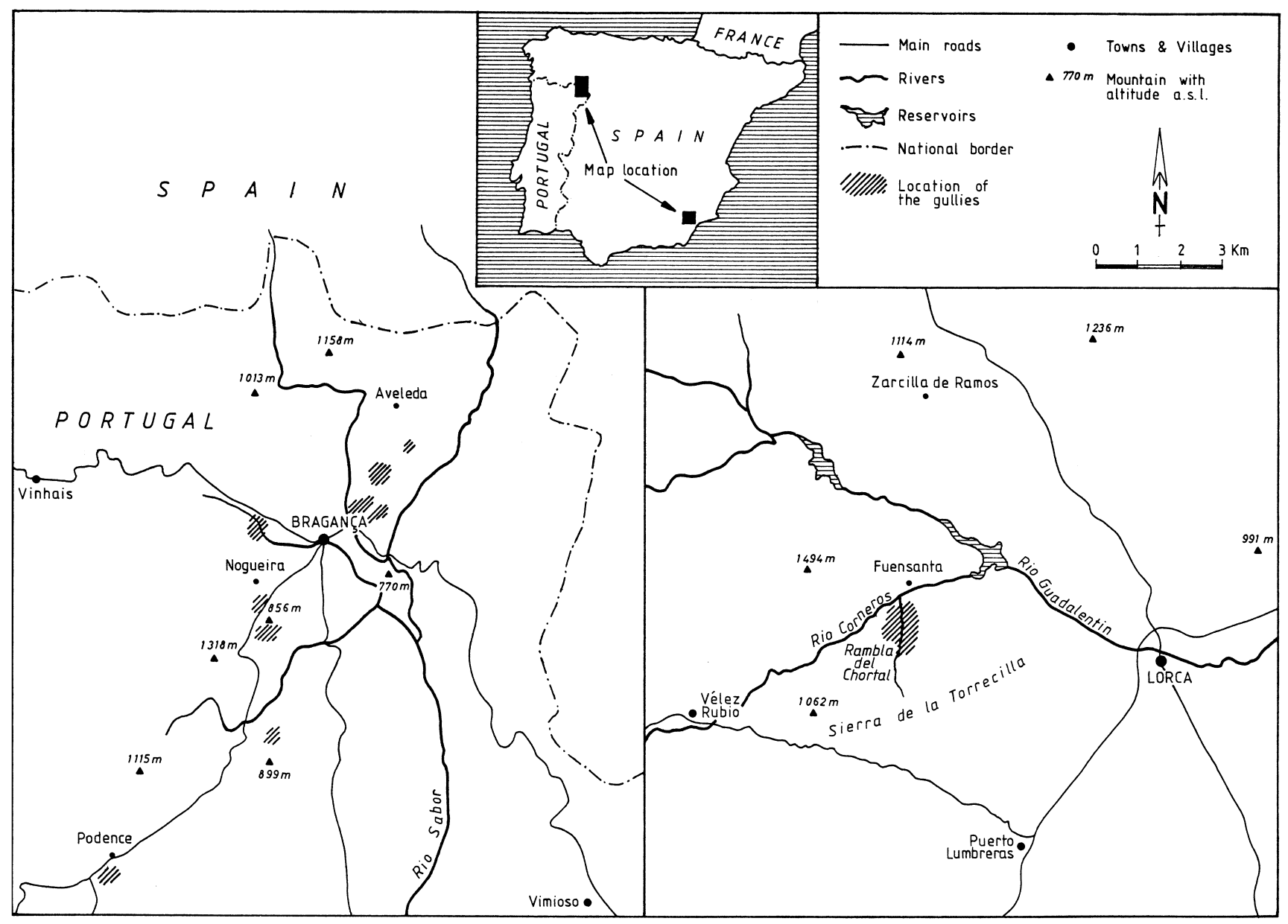

Fig. 1. Locations of the two study areas where data on ephemeral gullies have been collected. 


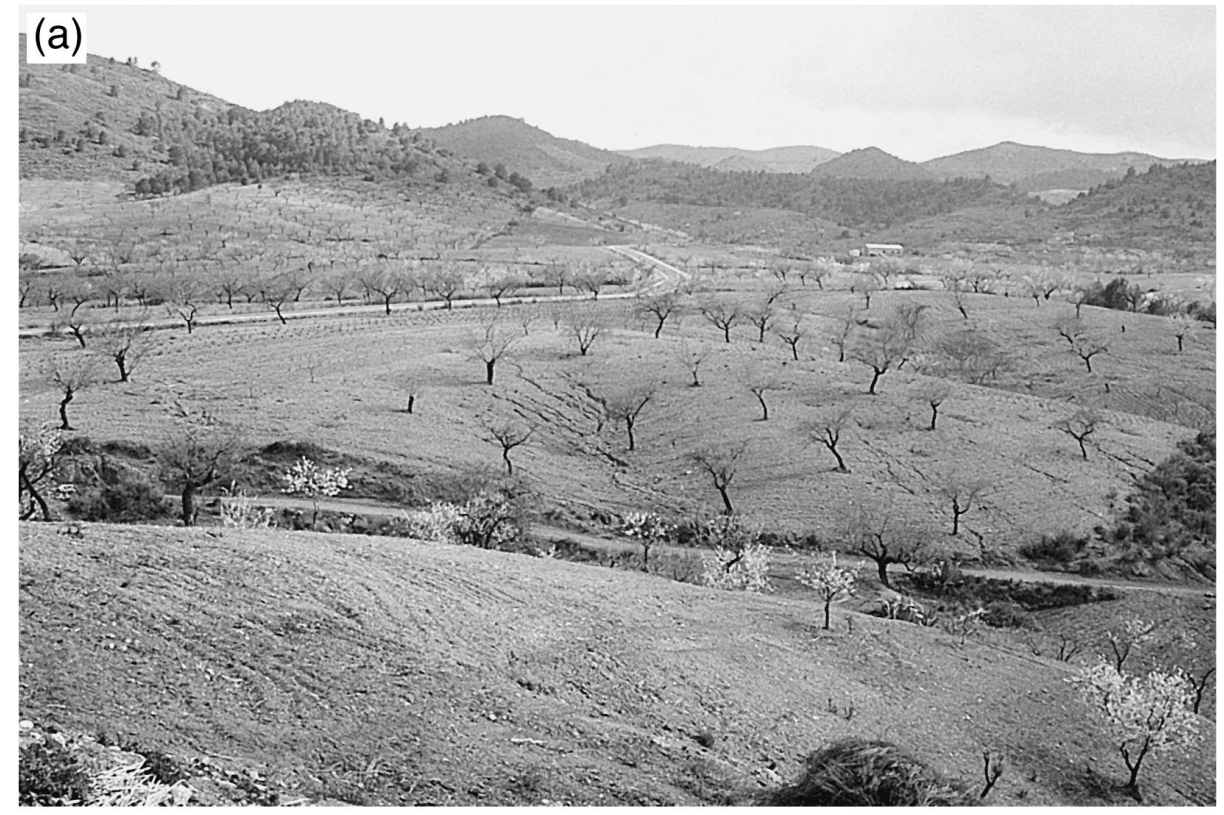

(b)

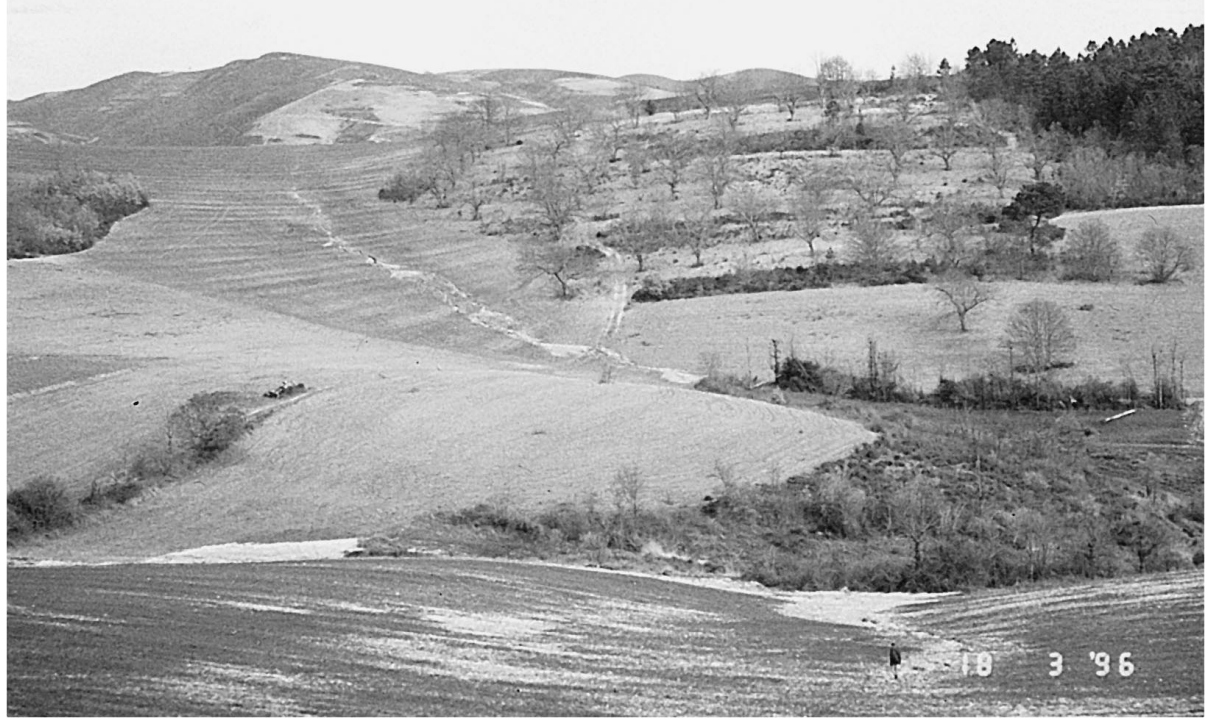

Fig. 2. Study areas in Spain (Sierra de Torrecilla): ephemeral gullies in intensively cultivated almond groves (a) and in Portugal (Bragança area): ephemeral gullies in intensively cultivated winter cereal fields (b). 
dominantly winter cereals (wheat or rye), permanent pasture in stream valleys, and sparse chestnut tree plantations. There is also the natural matorral vegetation, sometimes associated with Quercus or Pinus forests, and small areas with olive trees, vineyards or other orchards. The ephemeral gullies we studied had developed in fields of cereals sown between the first week of November and the first week of December 1995. The area has a Mediterranean sub-humid climate. Mean annual precipitation, measured in Bragança between 1984 and 1995, is $740 \mathrm{~mm}$.

The Spanish and Portuguese study areas therefore have both common and different environmental characteristics. These conditions are important and should be taken into account in the derivation and interpretation of threshold conditions for ephemeral gully initiation in these areas.

\section{Methods}

Field surveys in March 1996 identified fifty sites with an ephemeral gully in each study area. At every site the following quantitative and qualitative parameters were assessed. Local slope $(S, \mathrm{~m} / \mathrm{m})$ and source area $(A$, ha) of the rill-gully system were measured at the most upstream location where the cross-section of the incision reached $930 \mathrm{~cm}^{2}$. Other characteristics assessed at this 'critical cross-section' were estimated rock fragment content of the plough layer, estimated rock fragment cover at the soil surface, and exposure of bedrock or $\mathrm{a}_{\mathrm{t}}$ horizon in the gully bed. In the Portuguese study area, the topographical position of the gully in a distinct hollow or on a straight slope without topographical concentration of water flow was systematically recorded, as well as the tillage direction relative to the gully. In most cases, tillage lines were either perpendicular or parallel to the gully direction. A few examples were classified as having a combination of tillage directions where slightly oblique or perpendicular tillage lines occurred, at one site together with parallel ones.

The local slope of the soil surface $(S)$ was measured with an Abney level over a distance of 2 to $4 \mathrm{~m}$. The upstream drainage area $(A)$ was defined as the area from which overland flow was assumed to have reached the critical channel cross-section. The area was obtained by defining polygons in an upstream direction on both sides of the main streamline. For this purpose, a measuring tape was placed in the thalweg, from which the orthogonal distances to the catchment divide were measured at regular intervals. The total area was the sum of the areas of the individual polygons (quadrangles and triangles). The resulting area was not corrected for groundslope, and was therefore equivalent to the hydrologically efficient surface, i.e., the surface actually receiving rainfall and conveying overland or subsurface flow to the thalweg. The delineation of the drainage divide was based on evidence from the local topography and from microtopographical features, such as tillage marks and traces of flow paths draining into the ephemeral gully. In some examples, broken ridges clearly suggested the direction of overland flow. These methods render this field method more realistic than delineating the areas from topographical maps, which do not include local slope variations, temporary features such as plough furrows, and other linear elements. 
All collected data were used in a statistical analysis of the relationship between the two parameters drainage-basin area $(A, \mathrm{ha})$ and local slope $(S, \mathrm{~m} / \mathrm{m})$ within the Spanish and the Portuguese datatsets. We investigated how well the data fitted to the relationship $S=a A^{-b}$, formerly derived by Vandaele et al. (1996), and based on the 'shear stress indicator' of Begin and Schumm (1979). The definition of the threshold conditions is based on this relationship, and involves a statistical method consisting of two successive steps. First, the relationship $S=a A^{-b}$ was derived from our data by fitting a trend line through the datapoints using orthogonal regression on a double logarithmic scale. In contrast to ordinary regression (using least squares), the orthogonal regression technique (using total least squares) implies no specific role of any of the variables and provides a single predictive equation that can be used in either direction. This regression line minimises the deviations perpendicular to the line itself, and is obtained by the method of principal components (Jackson, 1991). The trendline is the first principal component between the logged values of $S$ and $A$, and is defined as the mean threshold line. Second, the lower limit of the $95 \%$ prediction confidence interval around the mean threshold line defines the minimum threshold line.

Finally, in order to compare our measurements with available literature data, the entire Spanish and Portuguese datasets and their respective minimum threshold lines were plotted together with threshold relationships derived from published datasets by Vandaele et al. (1996).

Moore et al. (1988) predicted the entire trajectory of ephemeral gullies using the indices $A_{\mathrm{c}} S$ and $\ln \left(A_{\mathrm{c}} / S\right)$, where $A_{\mathrm{c}}$ is the drainage-basin area per unit contour line $\left(\mathrm{m}^{2} / \mathrm{m}\right)$, and $S$ is the local slope $(\mathrm{m} / \mathrm{m})$. For our catchments, $A_{\mathrm{c}}$ has the same numerical value as the drainage basin area $(A)$ because the flow width at the measured gully cross-section was always $1 \mathrm{~m}$. For comparison, the indices have been applied to our data to see if they can also be used to describe the overall trend between $S$ and $A$ at the initiation points of the investigated ephemeral gullies.

\section{Results}

The environmental conditions characterising the Spanish and Portuguese study areas show some important similarities: in both areas, the ephemeral gullies had been formed in fairly stony soils, often with the bedrock at shallow depth, and the gullied agricultural fields were intensively cultivated and bare at the moment of incision. The soil had not been ploughed since the erosive events, so most of the rills, gullies and traces of overland flow were still present at the time of field data collection. Differences between the two study areas mainly arise from different lithologies and a different rainfall regime.

The gullies in Spain were formed during a rainfall event in September 1995, which lasted half an hour and caused severe erosion in the almond groves. This information was provided by a local farmer. The rainfall in this event was not measured at any of the 50 sites and extrapolation from measurements in the surrounding area was unreliable because of the very local nature of the event, as indicated by the very variable density of rills and gullies over short distances. However, at the weather station of Zarcilla de 
Ramos, a village $15 \mathrm{~km}$ north of the study area, the rain in 1995 was mainly concentrated in a few peaks of up to $36.5 \mathrm{~mm}$ per day in the summer and in 1996, another two storms of 20 and $19 \mathrm{~mm}$ per day occurred before the area was visited for this study.

The gullies in Portugal were caused by severe winter storms at the end of December 1995 and the beginning of January 1996, i.e. shortly after drilling the cereals. The rainfall, measured in Bragança between 1 November 1995 (i.e., just before drilling) and 16 March 1996 (i.e., the last rain day before the field survey) amounted to $882.3 \mathrm{~mm}$. This very high winter precipitation, greater than the long-term yearly average, included storms of up to $61 \mathrm{~mm}$ per day in late December 1995 and early January 1996. The large soil losses that resulted from these events are shown by the measured eroded volumes from some of the surveyed fields (Table 1).

Because of the differences between the Spanish and the Portuguese study areas, threshold conditions for ephemeral gully initiation were investigated separately and then compared with each other. The logarithmic plots with $S$ and $A$ for the respective datasets together with the fitted lines and their $95 \%$ prediction confidence intervals are shown in Fig. 3a and b. Table 2 summarises the results of the orthogonal regression for Spain and Portugal: the coefficient and exponent of the mean threshold relationships, the correlation coefficient $\left(R_{\mathrm{c}}\right)$, the coefficient of determination $\left(R_{\mathrm{d}}^{2}\right)$ and the significances $(P)$. According to a $t$-test, the correlation coefficient for the Spanish sites is not significant at the $10 \%$ level $(P=0.144)$, but is significant at the $0.22 \%$ level for Portugal.

The $95 \%$ prediction confidence interval around the fitted $S-A$ relationship would contain, with a chance of $95 \%$, the $S-A$ combination of a newly formed ephemeral gully if a similar rainfall event hit the same area. In only $5 \%$ of the gullied sites are the $S-A$ combinations less than the lower and greater than the upper confidence limit. Landscape positions with an $S-A$ combination less than the lower $95 \%$ confidence limit can be assumed to remain stable, except they may contain $2.5 \%$ of an unknown number of newly formed ephemeral gullies. Therefore, the $95 \%$ confidence limit is proposed as a minimum threshold line for ephemeral gully initiation.

Within the individual study areas, variations in environmental conditions have been accounted for by subdividing the datasets. The studied factors include: (1) the recorded soil characteristics at each gully site, and (2) the local topography and tillage direction relative to each gully for the Portuguese study area.

Table 1

Measured soil loss volumes due to rill and ephemeral gully erosion at some field sites in Northeast Portugal

\begin{tabular}{lllllll}
\hline Site & $\begin{array}{l}\text { Area } \\
(\mathrm{ha})\end{array}$ & $\begin{array}{l}\text { Minimum } \\
\text { thalweg } \\
\text { slope }(\%)\end{array}$ & $\begin{array}{l}\text { Maximum } \\
\text { thalweg } \\
\text { slope }(\%)\end{array}$ & $\begin{array}{l}\text { Total eroded } \\
\text { volume } \\
\left(\mathrm{m}^{3} / \mathrm{ha}\right)\end{array}$ & $\begin{array}{l}\text { Volume } \\
\text { of gullies } \\
\left(\mathrm{m}^{3} / \mathrm{ha}\right)\end{array}$ & $\begin{array}{l}\% \text { Gullies } \\
\text { volume }\end{array}$ \\
\hline 1 & 1.9 & 9 & 21 & 40.8 & 17.4 & 43 \\
2 & 4.11 & 4 & 17 & 7.9 & 6.0 & 77 \\
3 & 0.53 & 14 & 27 & 41.5 & 28.0 & 31 \\
4 & 2.23 & 7 & 23 & 33.6 & 2.9 & 63 \\
\hline
\end{tabular}


a

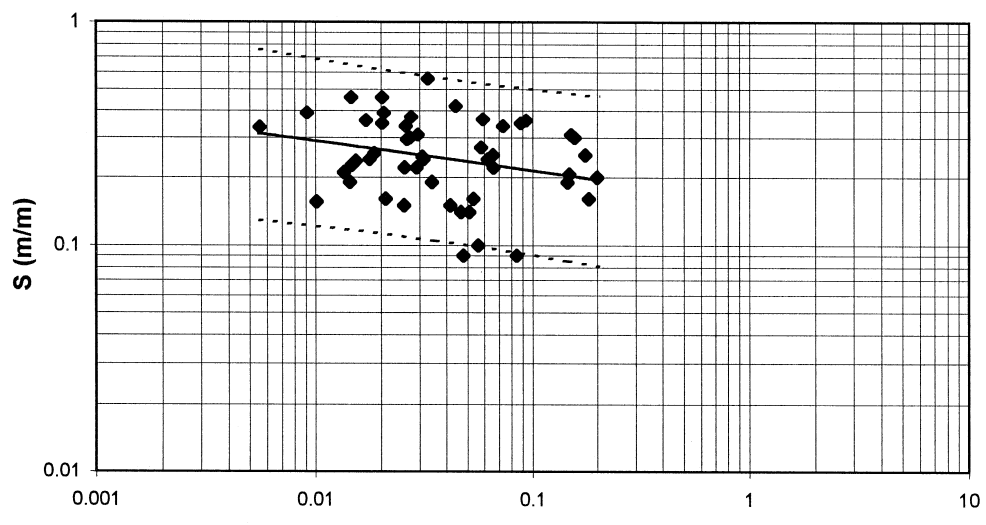

A (ha)

b

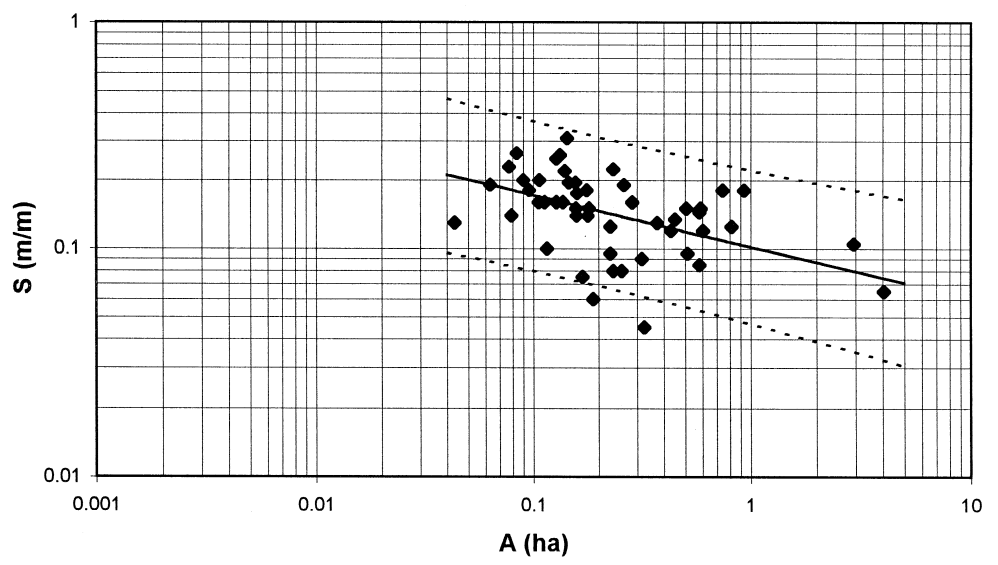

Fig. 3. Local slope $(S)$ versus drainage-basin area $(A)$ at the initiation point of the ephemeral gullies studied in Southeast Spain (a) and Northeast Portugal (b), the orthogonal regression line or mean threshold line (— $(-$ ), and the $95 \%$ prediction confidence interval (--). The minimum threshold line is the lower confidence limit.

\subsection{Soil characteristics at each site}

To investigate the influence of bedrock on the mean threshold relationship for both study areas, the sites where exposure of bedrock in the gully bed was observed were separated from those with no exposure. These groups have been distinguished in Fig. 4a and $b$. For both study areas, most data points with exposure of bedrock in the gully bed are situated in the upper part of the scatter plot, suggesting that a higher threshold level is required for incision of an ephemeral gully. In Spain, there were more sites with bedrock exposed (22) than in Portugal (17), and for both, the number with bedrock exposed was less than the number with no bedrock exposed (28 and 33, respectively). 
Table 2

Coefficient ' $a$ ', exponent ' $b$ ', the correlation coefficient $\left(R_{\mathrm{c}}\right)$, the coefficient of determination $\left(R_{\mathrm{d}}^{2}\right)$ and the significance $(P)$ of the mean threshold relationship $S=a A^{-b}$ for Spain $(n=50)$ and Portugal $(n=50)$

\begin{tabular}{llllll}
\hline Dataset & $a$ & $b$ & $R_{\mathrm{c}}$ & $R_{\mathrm{d}}^{2 \mathrm{a}}$ & $P^{\mathrm{b}}$ \\
\hline Spain & 0.157 & 0.133 & -0.209 & 0.057 & 0.144 \\
Portugal & 0.102 & 0.226 & -0.424 & 0.213 & 0.0022 \\
\hline
\end{tabular}

\footnotetext{
${ }^{\mathrm{a}}$ The coefficient of determination has been calculated using the error sums of squares that accounts for the variation of the observations in orthogonal direction to the regression line.

${ }^{\mathrm{b}}$ The significance for the correlation coefficient equals the $P$-value of the $t$-statistic: $t=R_{\mathrm{c}}[(n-2) /$ $\left.\left(1-R_{\mathrm{c}}^{2}\right)\right]^{1 / 2}$.
}

Regression analysis showed that subdividing the dataset improved the relationship between $S$ and $A$ for Spain, but not for Portugal. However, the significance levels were the same for the corresponding sub-datasets in both study areas, i.e., greater for sites without bedrock exposed $(P=0.05)$ than for sites with bedrock exposed $(P=0.09)$.

At seven sites in Portugal, a $B_{t}$ horizon was exposed in the gully bed. Omitting these datapoints from the original dataset improved the relationship from a significance level of $P=0.0022$ to $P=9 \times 10^{-4}$. This result indicates that, at the initiation of an ephemeral gully, the presence of a $B_{t}$ horizon at shallow depth weakens the relationship between $S$ and $A$ as does the presence of bedrock at shallow depth (see 4.1). To verify the similar effects of $a B_{t}$ horizon and bedrock, the datapoints with a $B_{t}$ horizon were shifted from the sub-dataset without bedrock to the sub-dataset with bedrock. The resulting relationships were more significant for the redistributed sub-datasets, i.e., $P=0.03$ for sites with neither bedrock nor $\mathrm{B}_{\mathrm{t}}$ horizon exposed, compared to $P=0.05$ for sites without bedrock but with a $\mathrm{B}_{\mathrm{t}}$ horizon, and $P=0.07$ for sites with either bedrock or a $\mathrm{B}_{\mathrm{t}}$ horizon exposed, compared to $P=0.09$ for sites with bedrock exposed but excluding those with a $B_{t}$ horizon exposed.

Subdivisions of the Spanish and the Portuguese datasets according to the estimated rock fragment content of the topsoil and rock fragment cover at the soil surface generally grouped the most stony sites in the upper part of the scatter plot. The significance of the $S-A$ relationships was not consistently high for all sub-datasets, but a visual interpretation of the plots suggests a higher threshold level for the more stony classes. Two examples are given in Fig. $4 \mathrm{c}$ and $\mathrm{d}$.

\subsection{Local topography and tillage direction at the Portuguese sites}

Subdividing the Portuguese dataset according to local topography and tillage direction relative to the gully (i.e., both natural and man-made features influencing the origin or direction of overland flow) improved the significance of the correlation between $\mathrm{S}$ and A in some examples (Tables 3 and 4). Table 3 shows that there were more 'hollow' situations (62\%) than 'straight slopes' (38\%). The gully direction was perpendicular to the tillage direction at $60 \%$, parallel to it at $24 \%$ and a combination of both at $16 \%$ of all the sites. Most of the gullies situated in hollows (77\%) were related to perpendicular tillage lines, which was overall the most frequently occurring situation, i.e., $48 \%$ of all 

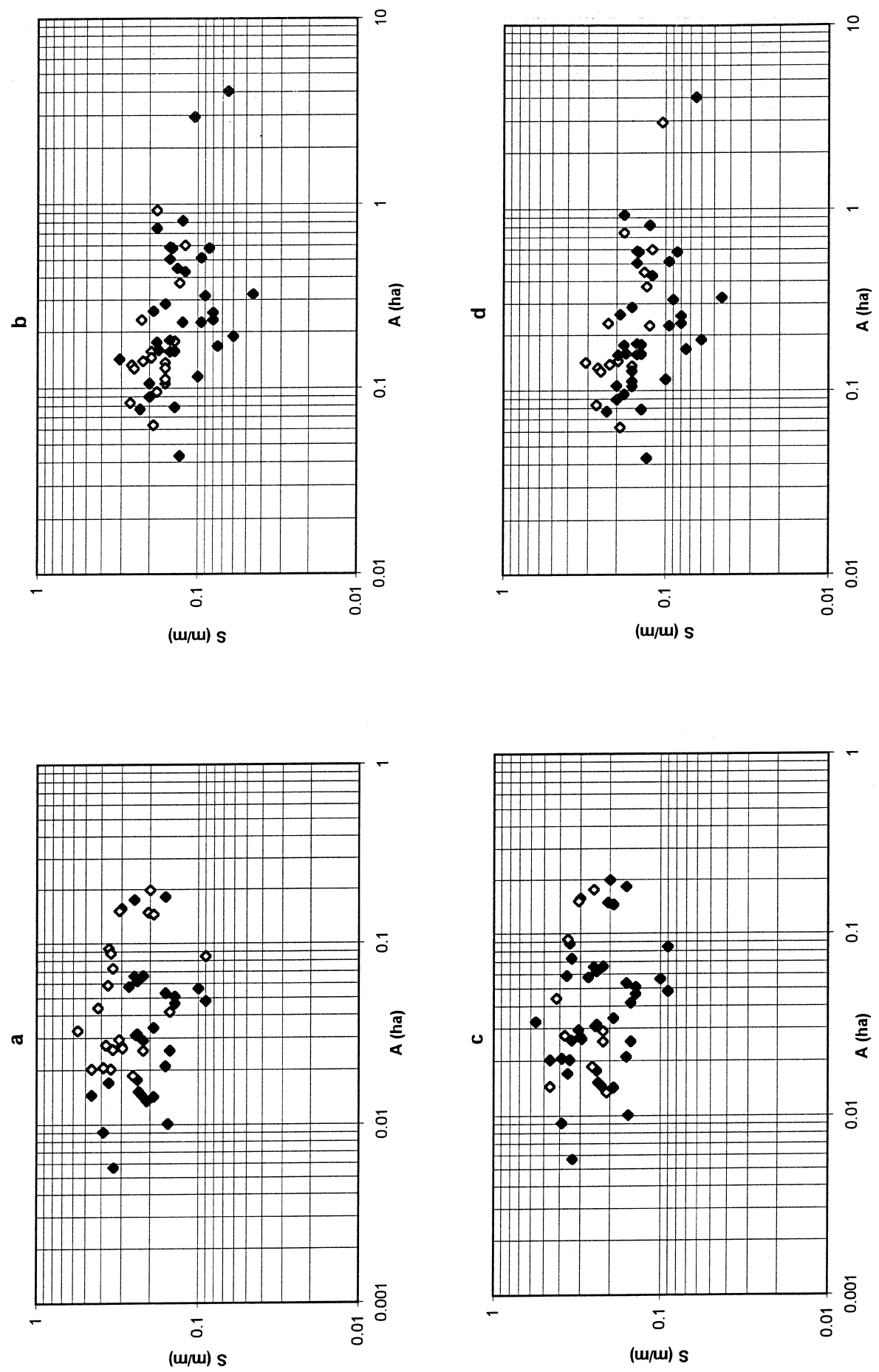
Table 3

Frequencies of topographic positions according to tillage direction within the Portuguese dataset

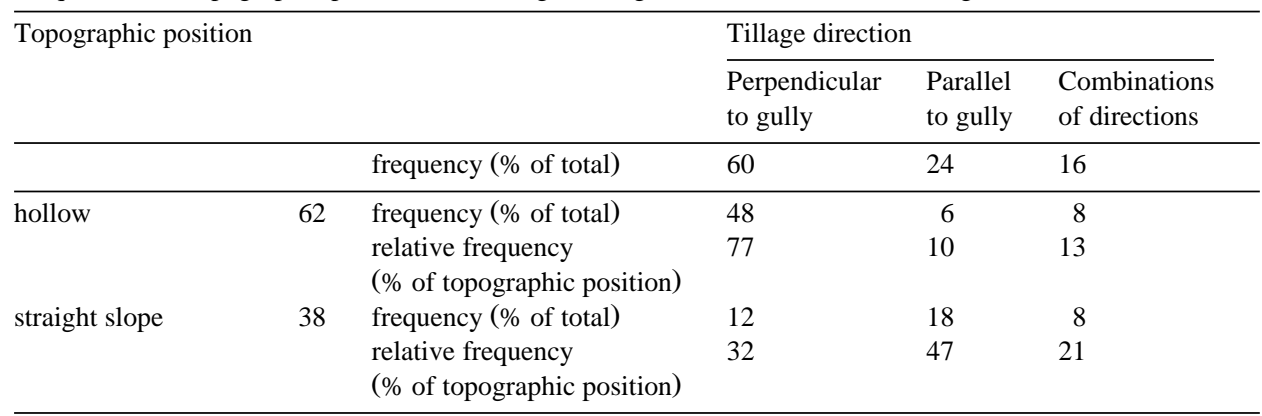

the sites. In contrast, $47 \%$ of the gullies situated on straight slopes were related to parallel plough lines, which was the second most frequent overall combination (18\%). $32 \%$ of the gullies on straight slopes showed perpendicular tillage lines (i.e., $12 \%$ of all the sites), and $21 \%$ showed a combination of both tillage directions (i.e., $8 \%$ of all the sites). In hollows, gullies related to both tillage directions occur more frequently (13\%, i.e., $8 \%$ of all the sites) than those related to parallel tillage lines $(10 \%$, i.e., $6 \%$ of all the sites).

Comparing the significance of the correlation between $S$ and $A$ in Table 4 with the corresponding value for the entire Portuguese dataset (i.e., $P=0.0022$, Table 3 ), the following conclusions can be drawn.

(1) Subdividing the dataset according to the topographical position of the gully results in a large improvement in the slope-area correlation for the hollow sites $(P=7.5 \times$ $10^{-5}$ ), whereas the correlation coefficient is not significant at any acceptable level for the gullies on a straight slope $(P=0.175)$.

(2) Subdividing the dataset according to the tillage direction results in acceptable correlations between $S$ and $A$ when the sites had been entirely tilled in one direction, but not when there was a combination of tillage directions. Compared to the entire dataset, this subdivision gave an improved significance level for the gullies perpendicular to the plough lines $(P=0.0011)$, a slightly decreased significance level for the gullies parallel to the plough lines $(P=0.016)$, and an unacceptable significance level for the gullies with plough lines in different directions $(P=0.75)$.

(3) The correlation between $A$ and $S$ for both the hollows and the straight slopes (see 1) is improved when these groups are divided according to the most frequently occurring plough directions in each situation. These are (i) plough lines perpendicular to a gully in a hollow $\left(P=1.85 \times 10^{-6}\right.$, compared to $\left.P=7.5 \times 10^{-5}\right)$; and (ii) plough lines parallel to a gully on a straight slope ( $P=0.022$, compared to $P=0.175)$. On the contrary, the

Fig. 4. Subdivisions of the original datasets according to soil properties: presence $(O)$ or absence $(\mathbf{O})$ of bedrock in Spain (a) and Portugal (b), estimated rock fragment content of the topsoil $<25 \%$ (O) or $\geq 25 \%$ $(\bigcirc)$ in Spain (c), and estimated rock fragment cover of the soil surface $\leq 20 \%(O)$ or $>20 \%(O)$ in Portugal (d). 
Table 4

Slope-area correlation coefficients $\left(R_{\mathrm{c}}\right)$, number of observations $(n)$ and significance levels $(P)$ of the sub-datasets obtained from the Portuguese dataset

\begin{tabular}{|c|c|c|c|c|}
\hline \multirow[t]{2}{*}{ Topographic position } & & \multicolumn{3}{|l|}{ Tillage direction } \\
\hline & & $\begin{array}{l}\text { Perpendicular } \\
\text { to gully }\end{array}$ & $\begin{array}{l}\text { Parallel } \\
\text { to gully }\end{array}$ & $\begin{array}{l}\text { Combinations } \\
\text { of directions }\end{array}$ \\
\hline \multirow{5}{*}{ Hollow } & & $R_{\mathrm{c}}=-0.565$ & $R_{\mathrm{c}}=-0.673$ & $R_{\mathrm{c}}=-0.133$ \\
\hline & & $\begin{array}{l}n=30 \\
P\end{array}$ & $\begin{array}{l}n=12 \\
P *=0016\end{array}$ & $\begin{array}{l}n=8 \\
P *=0754\end{array}$ \\
\hline & $R_{\mathrm{c}}=-0.650$ & $R_{\mathrm{c}}=-0.807$ & $R_{\mathrm{c}}=-0.783$ & $R_{\mathrm{c}}=-0.429$ \\
\hline & $n=31$ & $n=24$ & $n=3$ & $n=4$ \\
\hline & $P *=7.5 \cdot 10^{-5}$ & $P *=1.85 \cdot 10^{-6}$ & $P *=0.427$ & $P *=0.571$ \\
\hline \multirow[t]{3}{*}{ Straight slope } & $R_{\mathrm{c}}=-0.324$ & $R_{\mathrm{c}}=-0.292$ & $R_{\mathrm{c}}=-0.741$ & $R_{\mathrm{c}}=-0.271$ \\
\hline & $n=19$ & $n=6$ & $n=9$ & $n=4$ \\
\hline & $P *=0.175$ & $P *=0.575$ & $P *=0.022$ & $P *=0.729$ \\
\hline
\end{tabular}

* The significance for the correlation coefficient equals the $P$-value of the $t$-statistic: $t=R_{\mathrm{c}}[(n-2) /$ $\left.\left(1-R_{\mathrm{c}}^{2}\right)\right]^{1 / 2}$.
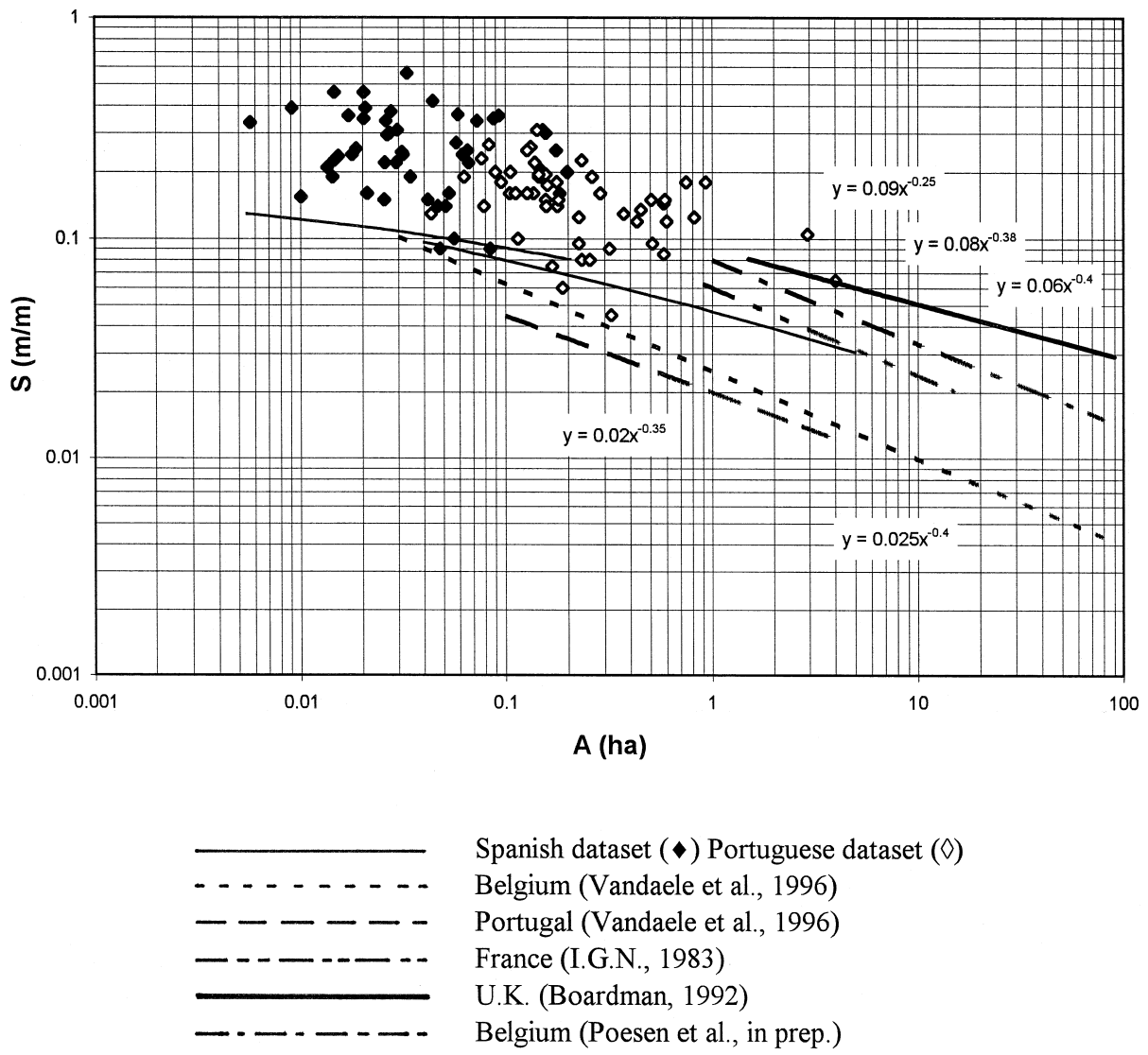

Fig. 5. Spanish and Portuguese scatter plots with respective minimum threshold lines together with those derived from previously published data by Vandaele et al. (1996). 


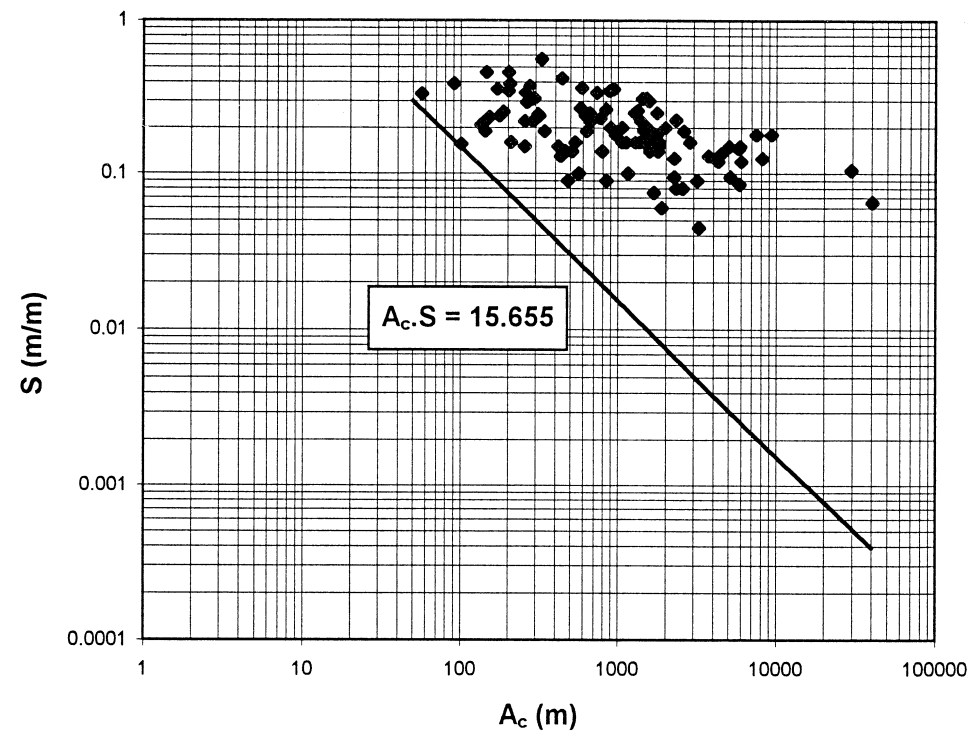

Fig. 6. Graphical representation of the index $A_{\mathrm{c}} S$ (Moore et al., 1988) compared with the combined dataset from Spain and Portugal.

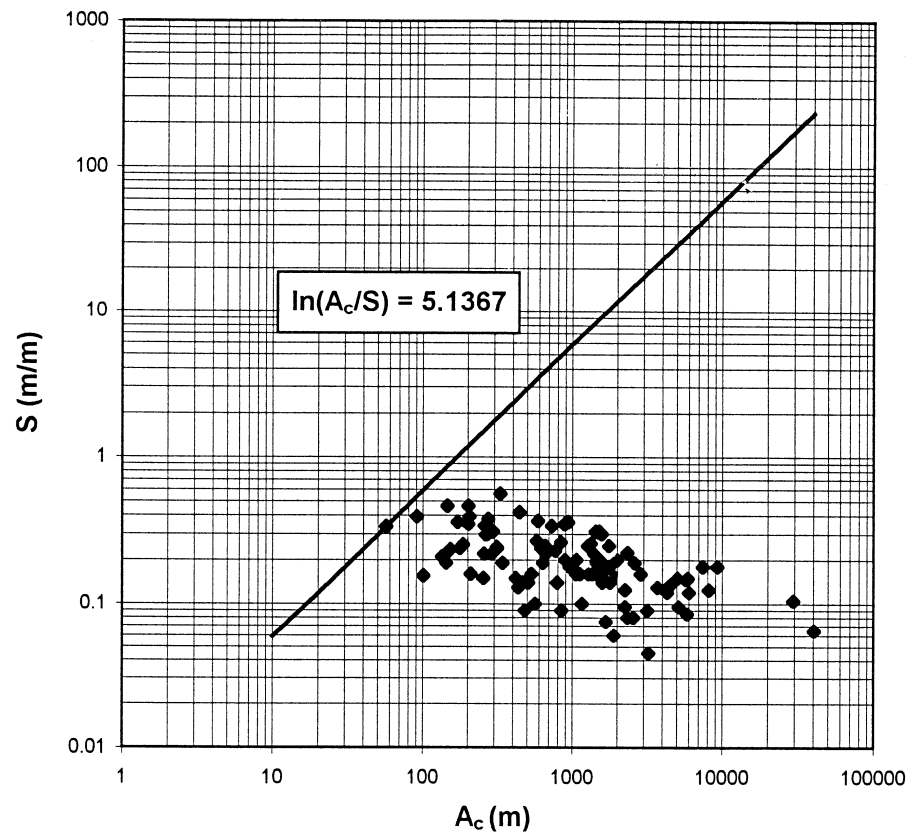

Fig. 7. Graphical representation of the $\operatorname{index} \ln \left(A_{\mathrm{c}} / S\right)$ (Moore et al., 1988) compared with the combined dataset from Spain and Portugal. 
relationships for the less frequently occurring combinations, such as plough lines parallel to a gully in a hollow, plough lines perpendicular to a gully on a straight slope, or a combination of plough directions in any topographical position, are not significant at an acceptable level.

Fig. 5 shows the integrated plot containing the entire Spanish and Portuguese datasets with their respective minimum threshold lines versus threshold relationships derived from literature by Vandaele et al. (1996). The calculation of the numerical values for the indices $A_{\mathrm{c}} S$ and $\ln \left(A_{\mathrm{c}} / S\right)$ (Moore et al., 1988) using our measured data for each gully initiation point resulted in a range of values within each dataset. The fitness of these indices was evaluated in relation to the overall trend that appears when both the Spanish and the Portuguese datasets are plotted together. The lowermost value for each index was taken as a threshold value and the corresponding threshold relationship was calculated. The suitability of the indices to describe the overall trend of the data can be evaluated in Fig. 6 for the index $A_{\mathrm{c}} S$, and in Fig. 7 for the index $\ln \left(A_{\mathrm{c}} / S\right)$.

\section{Discussion}

\subsection{Influence of physical factors on the significance of the mean threshold relationships}

Despite the use of standard methods for the measurement of drainage basin area and local slope (i.e., by means of a critical cross-section), the logged data are widely scattered. However, the scatter is comparable with the results from similar studies by Montgomery and Dietrich (1988), Prosser and Abernethy (1996) and Rutherfurd et al. (1997). The results of the statistical analysis raise two important questions: what causes the scatter around the established relationships, and why is it different between the Spanish and the Portuguese datasets?

Three physical explanations can be given for the low significance of the expected relationship between $S$ and $A$ within one study area. First, the large rock fragment content and cover and the presence of bedrock or a $B_{t}$ horizon at shallow depth may facilitate sub-surface processes because of high infiltration rates and deflection of flow by the less permeable horizons. Sub-surface flow involves a different relative role of $S$ and $A$, and hence weakens the assumed relationship for incision by overland flow if both processes operate together. This effect was shown by the statistical analysis of our own data, and equally by Faulkner (1995), who found poor correlations between gully parameters and simple topographical indices in similar soil conditions. Second, spatial variation in soil hydrological properties and in rainfall amount and intensity influence the amount and erosivity of overland flow generated from a certain drainage basin area. The concentration of overland flow furthermore depends on the shape and the planform curvature of the drainage-basin, which is not accounted for in the analysis of the entire datasets. Third, the contribution of the drainage-basin to overland flow production also varies in time, because flow paths to the gully initiation point deviate from or join the drainage-basin in the course of the event. However, this is difficult to assess after the event has taken place and implies an unavoidable error in the delineation of the drainage-basin area. 
The difference in significance between the Spanish and Portuguese regression lines is also related to these three physical factors. The influence of sub-surface processes was probably more pronounced in Spain because bedrock occurred more frequently and at shallower depths than in Portugal. Also in the Spanish region, the very high spatial and temporal variability of the rainfall may be partly responsible for the wide scatter and low significance of the relationship between $A$ and $S$. This rainfall characteristic is typical of the semi-arid climate of this area and contrasts with the more even distribution of frontal winter rains that are typical of the sub-humid climate in Portugal. This was also evident from the more equal density and wider spread of the ephemeral gullies in Portugal compared with Spain.

The statistical consequences of subdividing the Portuguese dataset according to hillslope topography and tillage direction include some interesting results concerning the influence of these factors on the studied processes (Table 4). The sub-datasets for which the significance of the correlation coefficient $\left(R_{\mathrm{c}}\right)$ was improved contain either gullies situated in hollows, gullies that developed perpendicular to the tillage direction, or a combination of these situations; the last gives the most significant relationship. The remaining subdivisions had less significance than the original dataset. A striking result is that for both hollows and straight slopes the relationship is considerably improved when the most frequently occurring tillage directions (i.e., perpendicular to the gully in hollows and parallel to the gully on straight slopes) are taken into account (Table 3). A physical explanation is that local topography and tillage marks may have an important influence on the efficiency by which overland flow is conducted to the initiation point of an ephemeral gully.

The best results are obtained when water is concentrated by a hollow, by tillage lines following the contour lines (i.e., perpendicular to a gully), and even better by a combination of the two. In these instances, it is less likely that the original flow paths are altered in the course of the event, implying a more constant contribution of the drainage-basin area and hence a smaller delineation error. In contrast, the probability of deviations of the flow lines from the original drainage-basin (and hence changes in $A$ ) is greater (i) when water is not concentrated by topography, as on straight slopes, and (ii) where the tillage direction does not coincide with the topographically determined flow direction (i.e., for gullies parallel to the tillage direction in hollows, or where gullies develop perpendicular to the tillage direction on straight slopes). Thus, water may start to flow according to the tillage direction, but later break through the ridges and follow its natural course (or vice versa). The synergetic effect of both factors determining flow direction seems to be important, as illustrated in particular by the combination of hollows with tillage direction perpendicular to the gully, and straight slopes with tillage direction parallel to the gully.

\subsection{Comparison of the minimum threshold relationships}

The position of the minimum threshold lines of the Spanish and the Portuguese datasets (Fig. 5) can be compared within the slope-area range in which they overlap. Because standard methods have been used to obtain the threshold relationships (including the identification of ephemeral gullies, the measurement of $S$ and $A$, and the 
statistical procedures), their position, i.e., the respective threshold level, should be entirely a function of environmental conditions (soil, land-use and climate). The Spanish dataset covers steeper slopes and smaller areas than the Portuguese dataset. In the overlapping parameter range, the minimum threshold line for Spain indicates a higher threshold level than for Portugal. Environmental factors explaining this difference are mainly those of soils and climate, as the land-use conditions were similar, resulting in a cultivated, bare soil surface at the moment of incision in both areas.

A greater rock fragment content of the topsoil or a greater rock fragment cover at the soil surface, which are often related to each other, tend to increase the threshold level (Fig. 4). In Spain, the estimated topsoil stoniness was on average greater and the presence of bedrock was more important than in Portugal. The climatic factor probably plays a crucial role, but cannot be quantified because of the lack of suitable rainfall data for the Spanish field sites. Nevertheless, the available information suggests that the rainfall in Spain was considerably less than in Portugal. As a given drainage-basin area in Spain would have generated less discharge than one of equivalent size in Portugal, a steeper slope would have been required for the formation of an ephemeral gully in the Spanish study area.

Comparison of the threshold conditions at our sites with those derived by Vandaele et al. (1996) (Fig. 5) is hampered because different methods were used to collect the data and to establish the minimum threshold relationships. In most instances, the effect of the data collection methods is difficult to discern from the effect of environmental factors. For example, the Portuguese and Belgian datasets of Vandaele et al. (1996) were obtained from aerial photographs, identifying gullies with a minimum width of $1 \mathrm{~m}$, and using a DTM for the measurement of drainage-basin area and slope. It is clear that these studies deal with larger incisions than those we investigated, whereas the use of a DTM may result in a systematic under-estimation of the local slope compared to measurements taken in the field (Vandaele et al., 1996). Our own experience also showed that the delineation of the drainage basins would have been quite different, but less realistic, if it had been based on topography alone.

The second methodological difference concerns the derivation of the minimum threshold relationship. Vandaele et al. (1996) plotted a line touching the data cloud through two points with the smallest values for both $S$ and $A$. This method is more arbitrary than our definition of the minimum threshold line according to the statistical trend and the $95 \%$ confidence interval of the entire dataset, and usually results in a different position of the threshold relationship.

Because of these difficulties, the comparison is restricted to the relative position of the scatter plots representing our data versus the other threshold lines in Fig. 5. The datapoints follow the negative trend of these threshold lines and seem to justify the extrapolation of the lowermost threshold levels (i.e., Belgium and Portugal, Fig. 5) in the greater slope and lower drainage-basin area ranges, as the points would still plot above the extended lines.

In theory, the slope ' $b$ ' representing the relative importance of drainage-basin area and local slope is physically determined by the process. Montgomery and Dietrich (1994) showed a sharp decrease in slope of the threshold relationship between $S$ and $A$ for slopes greater than $45 \%$ and areas smaller than 1 ha where landsliding occurs. 
However, the lower slopes of the mean threshold relationships we derived from our data compared with the steeper slopes up to 0.4 obtained by Vandaele et al. (1996) cannot be attributed to a change in process dominance because they were obtained by different methods. Montgomery and Dietrich (1994) also derived a theoretical exponent $b$ of $6 / 7$ or 0.86 for incision by turbulent Hortonian overland flow. Our study shows that the empirical derivation of a similar relationship does not give the same result.

A contrasting result is the correspondence with the relationship of Begin and Schumm (1979) for the prediction of discontinuous valley-floor gullies in semi-arid northwestern Colorado. They obtained $b$ values between 0.2 and 0.4 from a 'shear stress indicator', based on the definition of shear stress and some empirical relationships. The $b$-values we report in this paper range between 0.13 and 0.4 (Table 2 and Fig. 5), so that the semi-theoretical relationship of Begin and Schumm (1979) can be considered as a reasonable approximation to an empirically based relationship, by whatever method it has been established.

\subsection{Comparison with existing topographical indices}

Figs. 6 and 7 show that both the $A_{\mathrm{c}} S$ and $\ln \left(A_{\mathrm{c}} / S\right)$ indices fail to describe the general trend of the Spanish and Portuguese datasets plotted together. Moore et al. (1988) used a combination of both indices to predict the entire trajectory of ephemeral gullies in an Australian catchment. They obtained good results with the $\ln \left(A_{\mathrm{c}} / S\right)$ index as a measure of soil saturation in the upper part of the catchment, with shallow soils on bedrock. The $A_{c} S$ index performed well as a measure of concentrated surface flow on deeper soils in the lower parts of the catchment. This supported field observations that the ephemeral gullies were initiated by seepage forces, and were further developed by sediment transport and incision by concentrated surface flow.

One reason for the discrepancy between the trend described by our data and by the individual indices is that neither process took place individually at our study sites. In Spain and Portugal, concentrated overland flow was considered the main erosion process because no clear signs of seepage erosion were observed at the initiation point of the surveyed ephemeral gullies. However, sub-surface flow can be assumed at sites with shallow bedrock or a $\mathrm{B}_{\mathrm{t}}$ horizon in the soil profile. The $A_{\mathrm{c}} S$ index for overland flow implies a negative relationship between drainage-basin area and local slope, attributing an equal weight to $A_{\mathrm{c}}$ and $S$. The negative trend is reflected in the scatter cloud representing the combined Spanish and Portuguese data (Fig. 6), confirming the dominant role of overland flow in the incision process. However, the slope of the overall empirical trend is considerably less than 1 . This can be partly explained by the limited influence of subsurface flow, implying a positive relationship between $A_{\mathrm{c}}$ and $S$ (Fig. 7). It corresponds to the results obtained by Vandaele et al. (1997), who were able to predict the location of ephemeral gullies in Portugal, where soil conditions induced subsurface flow, by a combination of $A_{\mathrm{c}} S$ and $\ln \left(A_{\mathrm{c}} / S\right)$ using a geographical information system.

An additional interpretation is that, for the initiation of an ephemeral gully by overland flow, local slope has greater importance compared to drainage-basin area or discharge than it does for downstream development of the gully, as described by the 
$A_{\mathrm{c}} S$ index of Moore et al. (1988). Therefore, a modified version of this index is proposed: this is $A_{\mathrm{c}}^{b} S$, where $b$ is the slope of the empirically derived threshold relationship $S=a A^{-b}$. This index can be used to describe the topographical threshold conditions for ephemeral gully initiation in Mediterranean areas where similar erosion processes take place.

\section{Conclusion}

Our results illustrate the potential of the threshold concept for predicting ephemeral gully initiation using topographical information collected in the field. The empirical approach shows the need for information on the environment other than topography alone. This is indicated by the weak correlation between drainage-basin area and local slope measurements at the initiation point of ephemeral gullies, even when they are obtained by standard methods. Soil properties seemed to have an important influence on the relationship between drainage-basin area and local slope as well as hillslope topography and tillage direction. Comparison of our minimum threshold lines with those of previous studies confirms the lowermost published threshold levels, but was limited because other authors used different methods to collect the data and to derive the threshold line. The separate application of the indices $A_{\mathrm{c}} S$ and $\ln \left(A_{\mathrm{c}} / S\right)$ to our data does not provide a satisfactory description of the general trend between the considered parameters. This is because the indices were originally developed to model erosion by overland flow and seepage erosion along the entire trajectory of an ephemeral gully whereas we considered the initiation process by overland flow as the main erosion force. Instead, the index $A_{\mathrm{c}}^{b} S$, where $0.133 \leq b \leq 0.226$, according to the empirical trend between drainage basin area and local slope, is proposed. This index describes the topographical threshold conditions for ephemeral gully initiation in Mediterranean cultivated areas, where the main erosion force is overland flow and some subsurface flow may occur.

\section{Acknowledgements}

The research for this paper was part of the MEDALUS (Mediterranean Desertification and Land Use) collaborative research project, phase III. MEDALUS was funded by the European Commission Environment and Climate Research Programme (contract: ENV4-CT95-0118, Climatology and Natural Hazards) and this support is gratefully acknowledged. The study is also a contribution to the Soil Erosion Network of the Global Change and Terrestrial Ecosystems Core Research Programme, which is part of the International Geosphere-Biosphere Programme. We thank Prof. Mike Kirkby for his useful advise, Hein Prinsen and Eric Cammeraat for providing background rainfall data for the Spanish field site, and Herman Van de Straete for his contribution to the statistical analysis. The measurements of soil loss volumes caused by rill and ephemeral gully erosion in NE Portugal were made with the help of Jorge Araujo and the support of the Instituto Politécnico de Bragança; their contribution is gratefully acknowledged. 


\section{References}

Begin, Z.B., Schumm, S.A., 1979. Instability of alluvial valley floors: a method for its assessment. Transactions of the ASEA 22, 347-350.

Brice, J.B., 1966. Erosion and deposition in the loess mantled Great Plains. Medicine Creek drainage basin, Nebraska. U.S. Geol. Survey Prof. Paper 352 H, pp. 235-339.

Cabezas, F., 1996. Guadalentin Basin: water resources. In: MEDALUS II (Mediterranean Desertification and Land-Use, phase II). Final report covering the period 1 January 1991 to 30 September 1995. Project IV: Research and Policy Interfacing in Selected Regions. Contract EV5V-CT92-0166, pp. 168-192.

Cammeraat, L.H., Imeson, A.C., 1995. Soil erosion and land degradation: some preliminary results from the MEDALUS project. In: van der Leeuw, S. (Ed.), L'homme et la dégradation de l'environnement, Association pour la Promotion et la Diffusion des Connaissances Archéologiques. Sophia Antipolis, pp. 403-416.

Faulkner, H., 1995. Gully erosion in the coastal sierra de Lujar, S Spain. In: Conference on Erosion and Land Degradation in the Mediterranean, Proceedings, University of Aveiro, Portugal, 14-18 June 1995, pp. $77-88$.

Flanagan, D.C., Nearing, M.A., 1995. USDA water erosion prediction project. Hillslope profile and watershed model documentation. NSERL Report No. 10. USDA-ARS National Soil Erosion Research Laboratory, West Lafayette, IN, USA.

Geeson, N.A., Thornes, J.B., 1996. Mediterranean desertification and land-use. Executive summary, phase II. Commission of the European Communities, Directorate General XII Science, Research and Development.

Hauge, C., 1977. Soil erosion definitions. Calif. Geol. 30, 202-203.

Horton, R.E., 1945. Erosional development of streams and their drainage basin; hydrophysical approach to quantitative morphology. Geological Society of America Bulletin 56, 275-370.

Jackson, J.E., 1991. A User's Guide to Principal Components. Wiley, New York, pp. 4-12.

Kosmas, C., Danalatos, N., Cammeraat, L.H., Chabart, M., Diamantopulos, J., Farand, R., Gutiérrez, M., Jacob, A., Marques, H., Martinez-Fernandez, J., Mizara, A., Moustakas, N., Nicolau, J.M., Oliveros, C., Pinna, G., Puddu, R., Puigdefabregas, J., Roxo, M., Simao, A., Stamou, G., Tomasi, N., Usai, D., Vacca, A., 1997. The effect of land-use on runoff and soil erosion rates under Mediterranean conditions. Catena $29,45-59$.

Lopez-Bermudez, F., 1996. Guadalentin Basin: land-use and socio-economics. In: MEDALUS II (Mediterranean Desertification and Land-Use, phase II). Final report covering the period 1 January 1991 to 30 September 1995. Project IV: research and policy interfacing in selected regions. Contract EV5V-CT92-0166, pp. $193-226$.

Montgomery, D.R., Dietrich, W.E., 1988. Where do channels begin?. Nature 336, 232-234.

Montgomery, D.R., Dietrich, W.E., 1994. Landscape dissection and drainage area-slope thresholds. In: Kirkby, M.J. (Ed.), Process Models and Theoretical Geomorphology. Wiley, Chichester, pp. 221-245.

Moore, I.D., Burch, G.J., Mackenzie, D.H., 1988. Topographic effects on the distribution of surface soil water and the location of ephemeral gullies. Transactions of the ASEA 31 (4), 1098-1107.

Patton, P.C., Schumm, S.A., 1975. Gully erosion, northern Colorado: a threshold phenomenon. Geology 3, $83-90$.

Poesen, J.W., 1993. Gully typology and gully control measures in the European loess belt. In: Wicherek, S. (Ed.), Farm Land Erosion in Temperate Plains Environment and Hills. Elsevier, pp. 221-239.

Poesen, J.W., Hooke, J.M., 1997. Erosion, flooding and channel management in Mediterranean environments of southern Europe. Progress in Physical Geography 21 (2), 157-199.

Poesen, J.W., Vandaele, K., van Wesemael, B., 1996. Contribution of gully erosion to sediment production in cultivated lands and rangelands. In: Erosion and Sediment Yield: Global and Regional Perspectives (Proceedings of the Exeter Symposium, July 1996). IAHS Publ. No. 236, pp. 251-266.

Poesen, J.W., van Wesemael, B., Govers, G., Martinez-Fernandez, J., Desmet, P., Vandaele, K., Quine, T., Degraer, G., 1997. Patterns of rock fragment cover generated by tillage erosion. Geomorphology 18, 183-197.

Prosser, I.P., Abernethy, B., 1996. Predicting the topographic limits to a gully network using a digital terrain model and process thresholds. Water Resources Research 32 (7), 2289-2298. 
Puigdefábregas, J., Boer, M., del Barrio, G., Cueto, M., Armas, C., Vidal, S., 1996. Guadalentin Basin: terrain analysis. In: MEDALUS II (Mediterranean desertification and land-use, phase II). Final report covering the period 1 January 1991 to 30 September 1995. Project IV: research and policy interfacing in selected regions. Contract EV5V-CT92-0166, pp. 227-272.

Renard, K.G., Laflen, J.M., Foster, G.R., McCool, D.K., 1994. Modelling soil erosion. In: Lal, R. (Ed.), Soil Erosion Research Methods. Soil and Water Conservation Society, Ancony, IA, USA, pp. 127-158.

Rutherfurd, I.D., Prosser, I.P., Davis, J., 1997. Simple approaches to predicting rates and extent of gully development. In: Wang, S.S.Y., Langendoen, E.J., Shields, F.D. (Eds.), Proceedings of the Conference on Management of Landscapes Disturbed by Channel Incision. University of Mississippi, Oxford, pp. $1125-1130$.

Schumm, S.A., 1956. Evolution of drainage systems and slopes in badlands at Perth-Amboy. New Jersey Bulletin Geological Society America 67, 597-646.

Vandaele, K., Poesen, J., Govers, G., van Wesemael, B., 1996. Geomorphic threshold conditions for ephemeral gully incision. Geomorphology 16, 161-173.

Vandaele, K., Poesen, J., Marques de Silva, Govers, G., Desmet, P., 1997. Assessment of factors controlling ephemeral gully erosion in Southern Portugal and Central Belgium using aerial photographs. Z. Geomorph. N.F. 413, 273-287.

UNEP, 1994. United Nations Environmental Programme. United Nations conventions to combat esertification in those countries experiencing serious drought and/or desertification, particularly in Africa, Geneva, Switzerland.

USDASCS, 1992. United States Department of Agriculture and Soil Conservation Services. Ephemeral Gully Erosion Model (EGEM), User Manual. 